\title{
AEROPORTOS BRASILEIROS E A FISCALIZAÇÃO DE EMBARQUE SOB A ÓTICA DO TERRORISMO
}

\author{
Gustavo Borges Ferraz ${ }^{1}$ \\ Anna Paula Bechepeche ${ }^{2}$
}

\section{RESUMO}

A evolução da aviação e das aeronaves de grande porte provocaram o aumento no transporte de passageiros no âmbito global. É fato que os modernos aviões transportam elevado número de pessoas em um único translado. Por isso, a quantidade de combustível embarcado também é expressiva. Por outro lado, essas mudanças transformaram as aeronaves em possíveis mísseis dirigíveis carregadas de combustível, tornaram uma ferramenta para a propagação dos atos de terror. Terrorismo é um assunto bastante debatido em escala mundial. Frequentemente, esse tema é tratado nas mídias e os grupos terroristas ocupam lugar de destaque. A notoriedade da questão toma proporções significativas quando associado à aviação. Destarte, a discussão sobre terrorismo e aviação encontra-se ainda rasa, pouco sedimentada em ambientes acadêmicos, sobretudo, no Brasil, país pacífico. Todavia, da pouca expressividade de conflitos sociais e da frágil inspeção aeroportuária nesse aspecto, há de se pensar que o cenário nacional é passível e pode se tornar acessível para atentados terroristas. Essa pesquisa trata de verificar a delicada fiscalização dos aeroportos brasileiros, quanto ao embarque de passageiros e pertences suspeitos. São também objetos desse estudo apresentar a definição de terrorismo e mostrar combinações químicas que passam pelo sistema de fiscalização de bagagens. Verifica-se que em todos os atos terroristas envolvendo a aviação, não foram utilizados grande poder fogo para derrubar ou tomar controle da aeronave, sendo assim não houve dificuldade para embarcar as substâncias químicas ou objetos usados para executar o ato, o que tornar o Brasil um país vulnerável para possíveis atos terroristas.

Palavras-Chave: Explosivos. Segurança aérea. Segurança aeroportuária. Terrorismo

\footnotetext{
${ }^{1}$ Bacharel em Ciências Aeronáuticas da Pontifícia Universidade Católica de Goiás. Endereço eletrônico: borgesferrazgustavo@gmail.com

${ }^{2}$ Doutora em Química pela Universidade Federal de São Carlos (1996). Possui graduação em Física pela universidade Federal de Goiás (1988), mestrado em Física pela universidade de São Paulo (1991). Endereço eletrônico: abechepeche@yahoo.com.br
} 


\title{
BRAZILIAN AIRPORTS AND EMISSION CONTROL IN THE OPTICS OF TERRORISM
}

\begin{abstract}
The evolution of aviation and large aircraft has led to an increase in passenger transport globally. It is a fact that modern airplanes transport large numbers of people on a single transfer. Therefore, the amount of fuel shipped is also significant. On the other hand, these changes have turned the aircraft into possible fuel-laden dirigible missiles, and have become a tool for the spread of terror. Terrorism is a widely debated issue on a world scale. This issue is often dealt with in the media, and terrorist groups occupy a prominent place. The notoriety of the issue takes on significant proportions when associated with aviation. Thus, the discussion about terrorism and aviation is still shallow, little settled in academic environments, especially in Brazil, a peaceful country. However, given the low expressiveness of social conflicts and the fragile airport inspection in this respect, it must be thought that the national scenario is feasible and can be made accessible to terrorist attacks. This research tries to verify the delicate inspection of the Brazilian airports, regarding the embarkation of passengers and suspicious belongings. It is also the objects of this study to present the definition of terrorism and show chemical combinations that pass through the baggage inspection system. It is verified that in all the terrorist acts involving the aviation, was not used great fire power to overturn or to take control of the aircraft, being thus it was not difficult to embark the chemical substances or objects used to execute the act, what make Brazil a country vulnerable to possible terrorist acts.
\end{abstract}

Key Words: Terrorism. Airport Security.Explosives. Air Safety.

Artigo Recebido em 21/12/2017 e Aceito em 12/09/2018 


\section{INTRODUÇÃO}

Nos últimos anos, com a evolução da capacidade das aeronaves, o transporte aéreo, seja de passageiros ou de carga, se tornou em uma das opções mais utilizadas. Afim de garantir a segurança das operações aéreas, foram desenvolvidos, por organismos nacionais e internacionais procedimentos não apenas ligados diretamente a operação da aeronave, como também ao embarque de passageiros, bagagens o que intensificou a fiscalização aeroportuária.

Após o atentado terrorista ocorrido em 11 de setembro de 2001 nos Estados Unidos, houve uma transformação no sistema de fiscalização de passageiros e bagagens em nível mundial cujo objetivo era de mitigar qualquer chance de um novo atentado daquela proporção. No Brasil a aviação não acompanhou o progresso instaurado internacionalmente, assim, substâncias químicas ainda podem ser embarcadas sem dificuldade nos aeroportos brasileiros.

Ao longo do texto são apresentados conceitos e definições sobre terrorismo, as possíveis combinações químicas que podem ser transportadas sem dificuldade, bem como as fragilidades do sistema de fiscalização de passageiros e bagagens que pode levar a uma condição de exposição a possíveis atividades terroristas.

Tendo-se como base a fragilidade da fiscalização de bagagens e passageiros, o objetivo desta pesquisa foi identificar as falhas durante 0 processo de embarque, especificar combinações químicas que podem ser embarcadas de maneira inadequada e as mudanças no processo de fiscalização que resultem em uma melhora deste serviço. 


\section{METODOLOGIA}

A presente pesquisa foi organizada em duas seções, a primeira apresenta e relata acontecimentos considerados terroristas que ocorreram ao longo da história da aviação mundial, definir terrorismo e suas classificações. A segunda seção relata atos de terrorismo envolvendo o embarque de substâncias químicas, apresenta substâncias químicas que podem ser facilmente fabricadas e embarcadas devido as falhas da fiscalização dos aeroportos nacionais.

Afim de demonstrar a fragilidade do processo de fiscalização de bagagens, esta pesquisa sustentou-se em informações disponibilizadas por fabricantes dos equipamentos de Scanners ${ }^{3}$, testes realizados com os equipamentos e registros de incidentes que demonstram essa fragilidade.

Este trabalho foi elaborado a partir de uma pesquisa qualitativa e bibliográfica, utilizando ferramentas de busca como a plataforma Scielo e Google acadêmico. Foram pesquisados livros e artigos que abordam os assuntos terrorismo, química, história da aviação, direito aeronáutico, explosivo, processos judiciais que tratam ações terroristas, documentários, jornais com notícias referentes ao tema publicados no período de1928 à 2014.

\section{CONTEXTUALIZANDO O TERRORISMO}

Após os atentados de 11 de setembro de 2001, o mundo assistiu, via espaço midiático, um marco histórico sobre o terrorismo. Mas o que é terrorismo? Hoje muito se discute sobre estado Islâmico, Boko Haram, Al Quaeda, Talibã e pouco se sabe o que realmente motiva tais grupos e quando e onde eles podem atuar. A princípio, definir terrorismo é desafiador porque

\footnotetext{
${ }^{3}$ Scanner: Aparelho utilizado para criar imagens contendo informações de bagagens ou corpo de passageiros.
} 
envolve muitas variáveis entre elas o motivo do ataque, sendo este de motivo de direito comum, social ou político, âmbito espacial, podendo ser nacional, interno, ou internacional e quanto a sua execução pode ser de forma direta ou forma indireta.

\subsection{Um breve histórico do terrorismo}

Casella (2006) esclarece que as discussões sobre terrorismo começaram em nível internacional somente em 1926, por iniciativa do Governo Romeno, que chamou atenção da Sociedade das Nações e tentou organizar uma convenção internacional para universalizar a repressão ao terrorismo. Mas a Convenção, que foi sediada em Genebra só ocorreu após o atentado de Marselha de outubro de 1934, que provocou a morte do Rei Alexandre I da lugoslávia e do Presidente do Conselho da República Francesa. Em10 de dezembro do mesmo ano, o Conselho da Sociedade das Nações aprovou a elaboração de uma convenção, com objetivo de discutir estratégias preventivas e de contenção do terrorjuntamente com a criação de uma Côrte Penal Internacional,para julgar os atos terroristas praticados no mundo todo.

Desde a Convenção de Varsóvia ${ }^{4}$., muita discussão sobre o terrorismo passou a ocorrer, o que ainda deixa seu conceito contraditório. Desta forma, defini-lo depende de variáveis contextualizadas nos cenários diversos, devido ao fato de que este encontra-se diretamente ligado a conceitos e aspectos sociais e políticos em constante transformação. Rapoport (1984) afirma que seria difícil achar atividade terrorista em qualquer período histórico que influenciou mais a vida de uma comunidade do que os atos de Zealote-Sicarii, que aconteceu aproximadamente no ano de 70 d.C, também conhecidos como daggermen, eram extremistas separatistas que carregavam adagas escondidas em suas roupas e assassinavam pessoas que eram contra suas crenças.

${ }^{4}$ Realizada em 12 e outubro de 1929 estabeleceu regras relativas ao transporte aéreo internacional. 
Os Zelotes atuaram por aproximadamente 25 anos, um período curto, mas de enorme influência na história. Normalmente os terroristas religiosos estão preocupados com os membros de sua própria cultura religiosa, mas os Zelotes também tinham o objetivo de gerar um impacto em massa contra a população grega, que vivia na Judéia e contra os romanos que os governavam.

A revolta de Zelotes resultou na destruição do templo e da cidade de Jerusalém e de acordo com Josefo (1952) os Zelotes invadiram a fortaleza Masada (Israel), e mataram todos os romanos que lá se encontravam equando os romanos reconquistaram Masada, os Zealots que ali estavam cometeram suicídio em massa para não serem capturados.

Após os episódios de Masada, ao longo da história da humanidade, muitos atentados com vertente terrorista ocorreram, entretanto nenhum deles por um único motivo. De acordo com Casella (2006) não há como isolar a motivação terrorista, ela pode estar associada as questões religiosas, ao mesmo tempo em que se volta para as razões sociais ou políticas.

O atentado ao World Trade Center, em 2001 nos Estados Unidos, se tornou o mais expressivo acontecimento terrorista mundial dos últimos tempos. O episódio conhecido como ataque das "Torres Gêmeas", para além do número de vítimas fatais colocou a aviação como um meio de promoção de atentados terroristas, levando a reflexão: em qual momento da história recente, teve início a utilização de aeronaves como ferramenta para a realização de atentados terroristas?

De acordo com Miguez (2008) o primeiro ato terrorista do mundo envolvendo a aviação foi registrado no Brasil na cidade de Aragarças (Mato Grosso) no dia 2 de dezembro de 1959, cujo objetivo político era assassinar o então Presidente do Brasil Juscelino Kubitschek. O movimento foi liderado por Haroldo Coimbra Veloso e outros membros da força aérea, o tenente-coronel Geraldo Labarthe Lebre; o major-aviador Éber Teixeira Pinto; os capitãesaviadores Gerseh Nerval Barbosa, Próspero Punaro Barata Neto e Washington Amud Mascarenhas e ainda o tenente-aviador Leuzinger Marques Lima, e do 
Revista Científica do Corpo de Bombeiros Militar de Pernambuco

Seção 2 - Artigos de Opinião

Artigo publicado no Vol.04 №10 - Edição de JUL a DEZ 2018 - ISSN 2359-4837(online)

Versão on-line disponível em: $\underline{\text { http://www.revistaflammae.com. }}$

Exército, o coronel Luís Mendes da Silva e o capitão Tarcísio Nunes Ferreira e os civis, o engenheiro Charles Herba e o comerciante Roberto Rocha Sayão.

Como apresentado por Casella (2006) o ato terrorista é desencadeado por diversos motivos, e o acontecido em Aragarças, reforça essa ideia. Alguns membros das Forças Armadas, em 1950, motivados pela falta de informações sobre a aquisição de novos porta-aviões e quem seriam os pilotos das novas aeronaves da marinha, o resultado negativo sofrido na Revolta de Jacareancanga, em 1956, a renúncia da candidatura do presidenciável Jânio Quadros, a ascensão do movimento comunista no Brasil liderado por Leonel Brizola, foram os motivos apontados para o ato terrorista de Aragarças.

Pelo fato de Haroldo Veloso ser líder do movimento, o acontecido em Aragarças ficou conhecido como a Revolta Veloso. Segundo Miguez (2008) O aeroporto de Aragarças foi escolhido para a revolta por ser um aeroporto novo e não ter vias de acesso rodoviário asfaltadas, sendo quase impossível se chegar ao local de outra forma que não seja aérea. Para ilustrar, o trajeto da cidade de Iporá a Aragarças, tem aproximadamente cento e oitenta quilômetros, na época de estrada de terra, e seu percurso durava em torno de oito horas.

Neste episódio, Eber Teixeira Pinto sequestrou uma aeronave do modelo Constellation (Lockheed) da Panair do Brasil, enquanto voava no trajeto entre os Estados de Tocantins e Belém. A aeronave foi desviada para Aragarças, enquanto os coronéis João Paulo Moreira Burnier e Haroldo Veloso esperavam em solo a chegada do Constellation e outros companheiros.

O saldo da revolta foi de 4 aviões sequestrados, um Constellation, dois C-47 que eram usados pela Força Aérea Brasileira (FAB) e um avião Beechcraft. O objetivo era bombardear os palácios do Catete e das Laranjeiras no Rio de Janeiro onde o presidente se encontrava, e dominar as bases de Santarém e Jacareacanga, no Pará. O movimento durou apenas 36 horas, após seu fracasso seus líderes fugiram nos aviões para o Paraguai, Bolívia e 
Argentina, e só voltaram ao Brasil durante o governo de Jânio Quadros, onde foram julgados na Justiça Militar da $24^{\circ}$ Vara Criminal do Rio de Janeiro.

Todo esse movimento foi considerado um fracasso pela falta de organização de seus líderes e ao número de adeptos. Já existiam tropas do Exército Brasileiro posicionadas no aeroporto de Aragarças antes mesmo das aeronaves pousarem, Carlos Lacerda havia traído os revoltosos e feito uma ligação para Bento Gonçalves que avisou o Ministro da Guerra e mandou uma equipe de paraquedistas para o local. Este fato colocou o Brasil na vanguarda dos demais países, inaugurando um novo estilo de guerrilha, que seria usado futuramente em ações terroristas em atuações internacionais.

Após as Convenções internacionais realizadas entre 1937 até 1999, procurando uma maneira de prevenção e de julgamentos dos atos terroristas, não foi possível impedir o acontecimento do sequestro de quatro aeronaves no dia 11 de setembro de 2001.

O 11 de setembro ficou conhecido como uma das maiores atividades terroristas no mundo. De acordo com Sant'Anna (2005) um total de 19 homens sequestraram quatro aeronaves comercias americanas com o objetivo de colidircom o centro financeiro em Manhattan, o Pentágono, e o Capitólio dos Estados Unidos da América, prédio este que serve como centro legislativo do governo americano.

Dois aviões atingiram propositalmente o World Trade Center, matando todos a bordo da aeronave e muitos que trabalhavam no prédio, posteriormente com seu desmoronamento mais destruição e mortes foram provocadas. $O$ terceiro avião atingiu o Pentágono, sede do Departamento de Defesa dos Estados Unidos localizado em Washington, D.C.

Segundo Sant'Anna (2005) no quarto avião ocorreu uma luta entre os passageiros e os sequestradores para retomar o controle da aeronave. Muitos passageiros mantiveram contato com seus familiares durante o sequestro $e$ foram informados dos demais aviões que foram sequestrados e que se tratava de uma ação suicida. Os passageiros se juntaram e organizaram um plano de 
Revista Científica do Corpo de Bombeiros Militar de Pernambuco

Seção 2 - Artigos de Opinião

Artigo publicado no Vol.04 №10 - Edição de JUL a DEZ 2018 - ISSN 2359-4837(online)

Versão on-line disponível em: http://www.revistaflammae.com.

ataque, fervendo água e usando um trolley ${ }^{5}$ como aríete para derrubar a porta da cabine. Durante a luta os sequestradores resolveram jogar a aeronave no solo, o avião colidiu em um campo aberto em Shanksville a $930 \mathrm{~km} / \mathrm{h}$ e abrindo uma cratera de 20 metros de profundidade.

Em todos os aviões, os autores dos sequestros utilizaram apenas um estilete, spray de pimenta, gás lacrimogêneo e pedaços de argila que foram moldados com o formato de bombas, pois não foi encontrado nenhum resquício de material explosivo após a perícia. De acordo com a declaração do Federal Bureau of Investigation - $\mathrm{FBI}^{6}$. Durante uma das ligações feitas por um dos passageiros, foi relatado que havia dúvida se a bomba portada pelo sequestrador era verdadeira. Por falta de provas de que os terroristas teriam tentado infiltrar tais itens nos pontos de revista e de segurança do aeroporto, o $\mathrm{FBI}$ acredita que as bombas eram falsas.

Após o atentado terrorista de 11 de setembro houve um alto investimento em segurança, com o objetivo de diminuir as chances possíveis de um atentado terrorista dentro dos Estados Unidos. Mas o mesmo não se aplica no Brasil, que se apresenta muito precário no quesito de defesa contra atentados terroristas.

\subsection{As formas de terrorismo}

De acordo com Diniz (2004), o terrorismo é uma forma específica de luta política, um artifício com o objetivo de alterar rapidamente a correlação de forças. Tem como fim a meta política; utilizando o terror como instrumento de força; mas não a utiliza com o objetivo de alcançar sua meta de forma imediata e sim de causar uma alteração no comportamento do inimigo para permitir sua derrota. Existe uma diferença entre o terrorismo e pirataria, onde a pirataria é

\footnotetext{
${ }^{5}$ Equipamento utilizado para o armazenamento e transporte de alimentos a serem consumidos durante o vôo.

${ }^{6}$ Unidade de polícia do Departamento de Justiça dos Estados Unidos, servindo tanto como uma polícia de investigação quanto serviço de inteligência interno.
} 
Revista Científica do Corpo de Bombeiros Militar de Pernambuco

Seção 2 - Artigos de Opinião

Artigo publicado no Vol.04 №10 - Edição de JUL a DEZ 2018 - ISSN 2359-4837(online)

Versão on-line disponível em: http://www.revistaflammae.com.

definida como uma prática de ações violentas contra pessoas e destruição de bens com o objetivo de alcançar lucro particular. (PELLA, 1928 apud CASELLA, 2006, p. 161)

O terrorismo pode ser classificado sob três aspectos: o Subjetivo, o Espacial e a Execução (SOTTILE, 1938 apud CASELLA, 2006, p.39).

No terrorismo subjetivo o fator psicológico com intencionalidade é o que embasa a ação. Nesta modalidade é possível distinguir o terrorismo de direito comum, terrorismo social e o terrorismo político. O Terrorismo de direito comum é exercido por meio do terror, sem ter uma relação com aspectos políticos e/ou sociais. Como exemplo tem-se a chantagem e o terrorismo psicológico. O Terrorismo social se apresenta na imposição, geralmente, de forma violenta, de uma ideologia ou doutrina social, é o terrorismo "em nome de uma causa". No Terrorismo político a intencionalidade e propósito é a ordem política contra o Estado em qualquer uma de suas estruturas.

O Terrorismo espacial se refere ao contexto territorial em que ocorre. Se a preparação, execução, objetivos, os efeitos do ato acontecem dentro de um único país, temos o Terrorismo nacional ou interno. O Terrorismo internacional, que é frequentemente político, ocorre quando a preparação, execução e os sujeitos envolvidos estão ligados a países distintos.

Quanto ao aspecto de Execução temos o Terrorismo direto, que ocorre quando as ações praticadas visam diretamente o objetivo proposto, enquanto no Terrorismo indireto as ações buscam um benefício indireto ao objetivo traçado, por exemplo, a produção e uso de passaportes falsos para garantir a circulação de um terrorista de um país para o outro para a prática do ato.

\section{SUBSTÂNCIAS QUIMICAS EXPLOSIVAS}

\subsection{Possíveis combinações químicas que podem ser embarcadas e usadas em um ato terrorista}


Embarcar com substâncias químicas ou explosivos com o objetivo de realizar um ato terrorista não é uma ideia nova. Ramzi Yousef, citado como $O$ Químico por Sant'anna(2005), foi o organizador de um atentado terrorista ao World Trade Center em 1993. Yousef alugou uma van e a transformou em uma grande bomba móvel, utilizando as substâncias químicas nitrato de uréia e hidrogênio. Seu objetivo era destruir uma pilastra central do prédio e causar o desmoronamento das duas torres matando milhares de pessoas.

O terrorista, juntamente com seu grupo, estacionou a Van no subsolo do World Trate Center e detonaram a bomba. O poder da bomba não foi suficiente para derrubar o prédio, mas totalizou 6 mortes e mais de 1000 feridos. Para Sant'Anna (2005) o ato de Yousef contra o World Trade Center se tornou a principal inspiração para o futuro atentado de 11 de setembro 2001.

Após essa tentativa mal sucedida de ataque as Torres Gêmeas, Yousef planejou um ataque terrorista contra aeronaves. Sua ideia inicial era mobilizar um grupo de terroristas para embarcar em diferentes aviões e colocar bombas relógio para explodirem durante os vôos. Esse plano foi conhecido como "atentado de Bojinka" que não chegou a ser executado.

Bonner e Weiser (2006) relatam que como teste para executar o seu plano, Yousef embarcou no vôo da Philippine Airlines 434, com um relógio de pulso digital, modificado para servir como temporizador, uma garrafa de plástico para solução de lentes de contato com seu líquido substituido por nitroglicerina.

Durante o vôo da Philippine Airlines, entre a cidade de Manila e Cebu (Filipinas), a nível de cruzeiro, Yousef, no banheiro da aeronave, utilizou uma bateria e fios, que foram levados a bordo dentro do seu sapato, e montou uma bomba relógio utilizando nitroglicerina. $O$ terrorista instalou a bomba no assento 26k e desembarcou em Cebu.

No percursso entre Cebu e Tokyo, a bomba explodiu, matou um passageiro e deixou 10 gravemente feridos. A explosão causou danos aos comandos da aeronave, obrigando o comandante Eduardo Reyes a pousar a 
aeronave com limitações nos comandos. Após a investigação foi descoberto que a intenção da explosão era de atingir o tanque central da aeronave que deveria se encontrar abaixo do assento 26k, mas a Philippine Airlines usava uma configuração diferente do Boeing 747-283B fazendo com que $O$ assento $26 \mathrm{k}$ ficasse a frente do tanque central.

Esse atentado foi apenas mais um dos vários testes que Yousef fez para organizar o ataque de Bojinka. Ele acabou sendo preso devido a um incêndio em seu apartamento provocado por um erro durante a fabricação de uma bomba. No seu depoimento, Yousef mostrou-se muito preparado para realizar os ataques, principalmente pelo fato de ter analisado todo o sistema de segurança dos aeroportos.

Um aspecto relevante no depoimento de Yousef foi quanto a escolha da nitroglicerina, que segundo o terrorista, o embarque de tal substância dificilmente seria detectada pelo sistema de segurança dos aeroportos adotado na época.

Em 22 de dezembro de 2001, Richard Colvin Reid, ficou conhecido como Shoe Bomber por tentar embarcar com uma bomba escondida em seu sapato, colocando em risco a vida de 183 passageiros e 14 tripulantes. Richard Colvin se converteu para o islamismo ainda jovem e recebeu treinamento para se tornar um membro da Al-Qaeda. O terrorista tentou embarcar no vôo American Airlines Flight 63, que fazia a rota entre Paris (França) e Miami (EUA), usando um sapato equipado com plástico explosivo, mas sua aparência física chamou atenção dos policiais e ele acabou sendo preso. Richard não alcançou seu objetivo final que era derrubar o vôo 63 da American Airlines, e hoje são conhecidos outros exemplos na história onde houve o embarque de substâncias químicas e fabricação de uma bomba.

A utilização de substâncias químicas e suas combinações podem causar diferentes reações, provocando explosões, sejam elas sonoras ou de impacto, fumaça tóxica e incêndio, prejudicando a segurança de vôo e colocando a aeronave, seus tripulantes e passageiros em situação de risco. 
Revista Científica do Corpo de Bombeiros Militar de Pernambuco

Seção 2 - Artigos de Opinião

Artigo publicado no Vol.04 №10 - Edição de JUL a DEZ 2018 - ISSN 2359-4837(online)

Versão on-line disponível em: http://www.revistaflammae.com.

As explosões podem causar sérios danos a estrutura da aeronave provocando, inclusive, sua queda. De acordo com Silva (2007) explosivo é qualquer material que, quando sofre o processo de ignição por calor ou impacto, acontece uma rápida decomposição ou oxidação. O processo libera energia que fica armazenado na substância em forma de calor e luz, ou se transformando em espécies químicas gasosas que ocupam mais espaço que a forma original da substância. Devido essa expansão ser muito rápida, um grande volume de ar é deslocado pela expansão gasosa. Essa expansão acontece mais rápida que a velocidade do som, e então acontece o sonic $b^{b o m^{7}}$. Essa sucessão de acontecimentos explica os efeitos de uma explosão.

As explosões ocorrem de várias formas, por explosivos de alta ordem que sofrem detonação e explosivos de baixa ordem que queimam e o processo de decomposição pode ser classificado das seguintes formas (SILVA, 2007):

A) Combustão: é definido por um processo químico de oxidação que geralmente utiliza o oxigênio do ar. $O$ fenômeno acontece de maneira lenta com baixa velocidade e um exemplo que pode ser citado desse processo é a queima de um pedaço de carvão.

B) Deflagração: sua propagação acontece pela condutividade térmica. Na maioria das vezes com velocidade subsônica, nesse caso existe a participação não só do oxigênio do ar, mas também do oxigênio presente nas substâncias a serem queimadas. Podemos exemplificar este processo comparando a queima de um algodão comum e o algodão que passou por processo de nitração ${ }^{8}$, também conhecido por nitrocelulose. A queima do algodão normal acontece de forma mais lenta pois utiliza apenas o oxigênio do ar, já a nitrocelulose, utiliza o oxigênio do ar e o oxigênio armazenado após processo químico de nitração.

\footnotetext{
${ }^{7}$ Sonic Boom: Um som associado a onda de choque, criada por objetos que viajam com velocidade maior que a do som.

${ }^{8}$ A nitração é a introdução irreversível de um ou mais grupo nitro (NO2) em uma molécula orgânica.
} 
Revista Científica do Corpo de Bombeiros Militar de Pernambuco

Seção 2 - Artigos de Opinião

Artigo publicado no Vol.04 №10 - Edição de JUL a DEZ 2018 - ISSN 2359-4837(online)

Versão on-line disponível em: http://www.revistaflammae.com.

C) Detonação: é definida como uma reação química de decomposição que utiliza exclusivamente o oxigênio presente na respectiva substância a ser queimada, geralmente ocorre com uma velocidade de 1500 $\mathrm{m} / \mathrm{s}$ a $9000 \mathrm{~m} / \mathrm{s}$. Devido a grande quantidade de energia liberada durante $\mathrm{o}$ processo de detonação é criado uma onda de choque. $O$ deslocamento provocado pela onda de choque com uma frente e pressão muito elevada, criando um grande poder de ruptura como é ilustrado na figura 1.

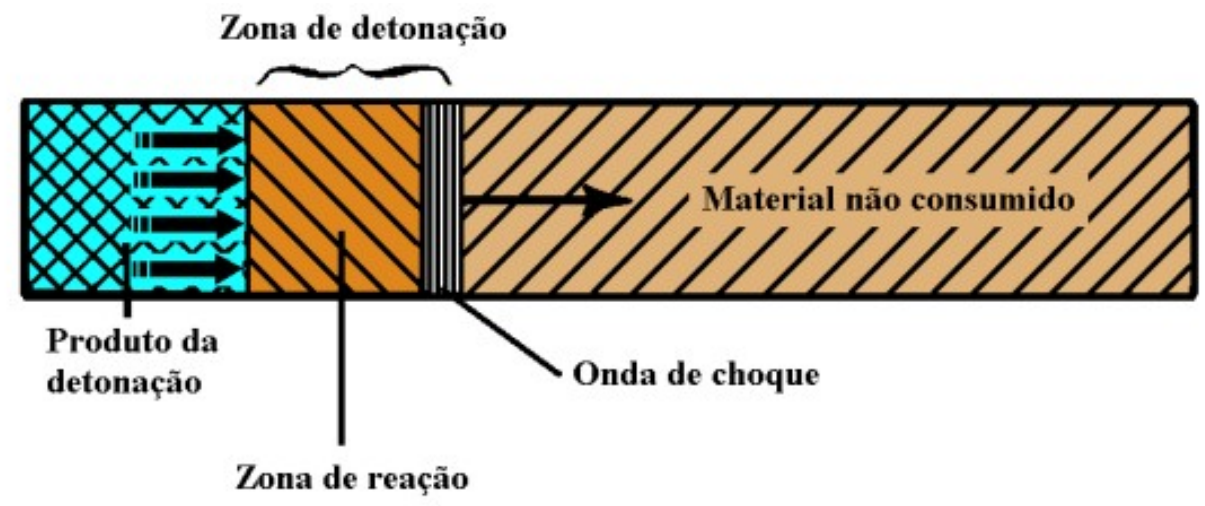

Figura 01: Esquema de uma detonação. (SILVA, 2007).

Existem inúmeras substâncias químicas com grande poder de explosão e que podem ser facilmente fabricadas e embarcadas. Como já foi citado anteriormente a nitroglicerina já foi utilizada em um atentado terrorista na aviação, por Yousef, na tentativa de executar o ataque terrorista de Bojinka, no entanto, nesta pesquisa foram encontrados relatos de outras substâncias que dificilmente podem ser detectadas pelos sistemas de segurança dos aeroportos e que possivelmente podem ser usados para atos de terrorismo.

A fabricação de explosivos é algo relativamente simples e uma das substâncias mais utilizadas para a sua fabricação é o ácido nítrico. Esta substância na sua forma pura não é um explosivo, pois $98 \%$ da sua composição é água (POWELL, 1971. p.113.), mas quando combinado com outras substâncias, o ácido nítrico torna a solução instável e de fácil explosão, processo químico conhecido como nitração. 
A glicerina é a substância mais conhecida para um processo de nitração. A adição de ácido nítrico à sua composição forma a nitroglicerina, utilizada pela primeira vez como explosivo em 1847 por Ascanio Sobreno. A Nitroglicerina é um dos explosivos mais sensíveis, se não for o mais sensível. Muitos terroristas já morreram ou ficaram gravemente feridos durante 0 processo de fabricação dessa substância. Mesmo assim é possível fabricá-lo de maneira segura. Na fabricação da nitroglicerina é usado água destilada, tabletes de sal, bicarbonato de sódio, nitrato de ácido concentrado, ácido sulfúrico concentrado e glicerina.

Outros produtos explosivos que podem ser fabricadas com certa facilidade, de acordo com Powell (1971), são:

A) Triodeto de amônia, pode ser encontrado na forma de pó ou em forma de cristal. É uma substância na cor roxa que pode ser detonada facilmente por calor, friç̧ão ou impacto. Sua detonação provoca um alto barulho de explosão, uma forte onda de impacto e libera uma fumaça roxa de gás de iodo. Um terrorista poderia utilizar essa substância em pequena quantidade para criar uma distração ou até com o objetivo de ferir pessoas, já que seu tamanho é bastante reduzido, mas o barulho e a onda de impacto é muito alta. Para fabricação de Triodeto de amônia é preciso somente cristais de iodo, amônia e hidróxido de amônia.

B) Fulminato de mercúrio: é talvez um dos mais antigos compostos para iniciação de uma grande bomba. Pode ser detonado por calor ou impacto, o que o torna uma substância de grande valor para os terroristas. Até mesmo a ação de deixar um cristal desses cair, pode gerar uma explosão. Seu tamanho é bem reduzido e bastante semelhante ao Triodeto de amônia. Para a fabricação do Fulminato de mercúrio é preciso mercúrio, ácido nítrico concentrado, álcool etílico e água destilada. Sua forma pode ser de cristal ou semissólido com viscosidade semelhante a uma pasta que diminuiu um pouco a sensibilidade da substância para sofrer detonação, mas que pode ser facilmente detonada com uma simples faísca gerada por uma bateria e fios, 
processo semelhante utilizado por Yousef no atentado de Bojinka ao detonar um frasco com glicerina.

C)Nitrocelulose ou também conhecida como algodão pólvora. É mais estável que a pólvora e produz mais calor durante sua queima. Também queima muito mais rápido que a pólvora quando é confinada em um recipiente. Para sua produção é necessário algodão (celulose), ácido nítrico concentrado e ácido sulfúrico concentrado. Sua aparência é de um algodão comum, por esse motivo seu embarque pode ser feito de maneira muito fácil se colocado em camadas internas de uma roupa por exemplo. A nitrocelulose pode ser usada como detonador primário de uma substância com maior poder de explosão, na fabricação de bombas de fumaça ou de bombas incendiarias. Stefanidou; Athanaselis; Spiliopoulou, (2008), afirmam que a maioria das fatalidades provocados por incêndios não são em decorrência de queimaduras, mas sim consequência da inalação de gases tóxicos produzidos durante a queima de materiais usados para decoração e estruturação de ambientes.

D)Bomba de cloro: é um exemplo claro de uma união entre duas substâncias químicas muito simples que com apenas a junção de cloro granulado e pequenas quantidades de álcool se transforma em uma bomba relógio, devido o tempo que demora para as substâncias se misturarem, essa bomba apresenta um baixo poder de impacto, mas provoca um alto estrondo no momento em que rompe o recipiente onde estiver armazenado. Esse exemplo pode ser classificado como uma explosão química, que é o resultado de uma reação físico-química, onde a velocidade muito alta da reação acontece juntamente por uma brusca elevação de temperatura e pressão, isso acontece pelo fato da energia liberada pela reação em cadeia acontecer em um tempo muito pequeno o que dificulta sua dissipação durante a sua produção.

E)Bomba de fumaça: por ser um processo muito simples de fabricação e utilizar substâncias de fácil aquisição, pode ser feito de várias maneiras diferentes. A forma mais discreta encontrada foi a utilização de um jornal, açúcar e Nitrato de potássio que pode ser encontrado em casas 
Revista Científica do Corpo de Bombeiros Militar de Pernambuco Seção 2 - Artigos de Opinião

Artigo publicado no Vol.04 №10 - Edição de JUL a DEZ 2018 - ISSN 2359-4837(online)

Versão on-line disponível em: http://www.revistaflammae.com.

agropecuárias já que são usados como fertilizante. Fazendo uma solução com água e usando uma razão de 3 unidades de açúcar para cada 5 unidades de Nitrato de potássio e mergulhando o jornal nessa solução e após o jornal secar, teremos um jornal que quando entrar em contato com o fogo vai se tornar uma bomba de fumaça, mas com uma aparência de um jornal comum. Isso acontece devido o açúcar atrapalhar a queima do papel, o processo de queima se torna mais lento e devido a adição de oxigênio proveniente do Nitrato de potássio acontece uma grande liberação de gás carbônico gerando uma grande quantidade de fumaça.

Powell (1971) apresenta as particularidades básicas das substâncias químicas citadas quanto as suas capacidades de gerar ondas de choque e ondas sonora, poder de incêndio, a produção de fumaça e a capacidade de detonação e explosão.

Quadro 1: Substâncias químicas e suas particularidades

\begin{tabular}{|l|c|c|c|c|c|}
\hline Substâncias & $\begin{array}{l}\text { Onda de } \\
\text { choque }\end{array}$ & $\begin{array}{l}\text { Onda } \\
\text { Sonora }\end{array}$ & $\begin{array}{l}\text { Poder } \\
\text { incendiário }\end{array}$ & $\begin{array}{l}\text { Produção } \\
\text { de fumaça }\end{array}$ & $\begin{array}{l}\text { Fácil } \\
\text { detonação }\end{array}$ \\
\hline Nitroglicerina & Alta & Alta & Baixo & Baixo & Sim \\
\hline Triodeto & Alta & Alta & Baixo & Médio & Sim \\
\hline $\begin{array}{l}\text { Fulminato de } \\
\text { Mercúrio }\end{array}$ & Alta & Alta & Baixo & Médio & Sim \\
\hline Nitrocelulose & Baixa & Baixa & Alto & Baixa & Sim \\
\hline $\begin{array}{l}\text { Cloro e } \\
\text { Alcool }\end{array}$ & Média & Alta & Baixo & Baixa & Sim \\
\hline $\begin{array}{l}\text { Bomba de } \\
\text { Fumaça }\end{array}$ & Baixa & Baixa & Médio & Alta & Sim \\
\hline
\end{tabular}

Fonte: POWELL, 1971. 
Revista Científica do Corpo de Bombeiros Militar de Pernambuco

Seção 2 - Artigos de Opinião

Artigo publicado no Vol.04 №10 - Edição de JUL a DEZ 2018 - ISSN 2359-4837(online)

Versão on-line disponível em: http://www.revistaflammae.com.

Todas as substâncias citadas anteriormente são de fácil embarque nos aeroportos pelo fato de se encontram no estado sólido ou líquido, que podem ser armazenado sem recipientes plásticos, em determinadas partes do corpo ou até mesmo nas próprias vestimentas.

\section{NOVOS PROCEDIMENTOS}

Após o atentado World Trade Center, entre as medidas que visam aumentar a segurança aérea podemos citar a fiscalização de bagagens e passageiros. A mais recente inovação tecnológica na questão de segurança e proteção foi introduzida no Reino Unido em 2010, o denominado scanner corporal ou o scanner humano. O passageiro é escolhido conforme critérios pré-estabelecido ou por comportamento suspeito, sendo conduzido a uma cabine, onde recebe raios eletromagnéticos, geram uma imagem em 3-D, sendo possível, assim visualizar armas e drogas, inclusive se ingeridas (SANTANNA, 2013).

Nos aeroportos do Brasil o scanner corporal é utilizado para o embarque internacional no aeroporto Antônio Carlos Jobim (Rio de Janeiro). De acordo com uma reportagem da Folha de São Paulo (2010), o passageiro ao passar pelo aparelho tem seu corpo submetido a ondas milimétricas que podem tornar transparentes camadas leves de roupas. Um receptor coleta os sinais refletidos e os direciona a um computador, responsável por processar os dados e gerar uma imagem tridimensional dos indivíduos submetidos ao aparelho.

A respeito do uso de scanners em aeroportos, sobre a eficiência e a eficácia da utilização do 'scanner corporal' para detectar substâncias em atos terroristas foi muito criticada. Questionada sobre este aspecto a Agência de Segurança dos Transportes Americana (TSA), se recusou a divulgar publicamente os resultados que indicariam o grau de precisão com que os scanners detectam explosivos e outras ameaças que podem derrubar uma 
Revista Científica do Corpo de Bombeiros Militar de Pernambuco Seção 2 - Artigos de Opinião

Artigo publicado no Vol.04 №10 - Edição de JUL a DEZ 2018 - ISSN 2359-4837(online)

Versão on-line disponível em: http://www.revistaflammae.com.

aeronave, desta forma os legisladores que tiveram acesso a esses resultados de desempenho, consideraram os mesmos decepcionantes.

Outras justificativas para as dificuldades dese detectar e identificar as substâncias citadas nesta pesquisa está na capacidade de leitura dos aparelhos de Raio-Xe dos Scanners. Segundo Roberto Sergnese, presidente da Simulscan, empresa responsável pelo treinamento e produção dos equipamentos de scanner de bagagens, em uma entrevista à revista Wired (2015), destacou que os aparelhos utilizados nos aeroportos para realizar uma leitura das bagagens são bastante limitados já que sua leitura é feita através de densidade dos materiais, não de suas propriedades, gerando diferentes cores para diferentes densidades das matérias, e que em alguns casos é impossível identificar o conteúdo da bagagem devido as tonalidades da mesma.

Para comprovar a dificuldade na identificação de objetos, apresenta-se a imagem da figura 2, que mostra um embarque de uma arma de fogo. Alocada de maneira estratégica na bagagem de mão, a arma de fogo poderia ser facilmente camuflada pelos demais objetos transportados na bagagem e somente com muita atenção e experiência pode ser identificada.
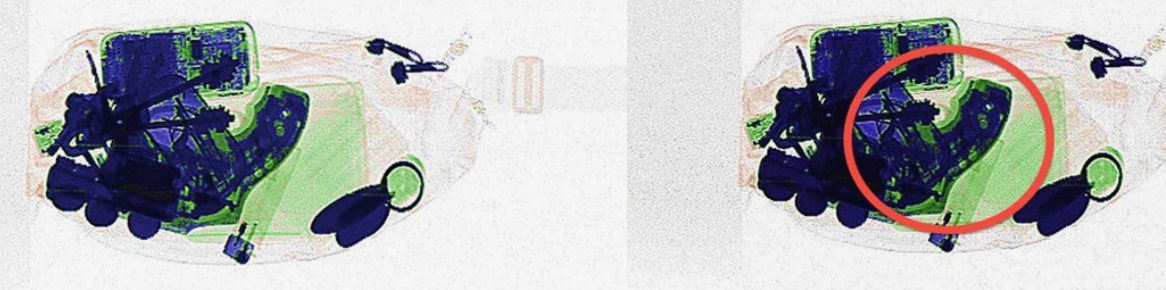

Figura 02: Revólver escondido em uma bagagem. (SIMULSCAN, 2015).

Um estudo feito pela universidade da Califórnia em San Diego (EUA), juntamente com a universidade de Michigan (EUA) com a Johns Hopkins 
Revista Científica do Corpo de Bombeiros Militar de Pernambuco Seção 2 - Artigos de Opinião

Artigo publicado no Vol.04 №10 - Edição de JUL a DEZ 2018 - ISSN 2359-4837(online)

Versão on-line disponível em: http://www.revistaflammae.com.

(EUA), mostrou a fragilidade dos scanners corporais da empresa Rapiscan System, apontou que o sistema de segurança pode ser facilmente violado.

$\mathrm{Na}$ figura 3 a seguir é apresentado uma foto que ilustra a dificuldade de identificação de uma arma de fogo sendo transportada no corpo de um passageiro submetido ao scanner. A duas imagens do lado esquerdo mostram a mesma pessoa de frente e de costas sem portar nenhuma arma de fogo. Nas imagens do lado direito mostra a mesma pessoa de frente e de costas portando uma arma de fogo. A arma, uma. $380 \mathrm{ACP}$, é transportada na região lateral direita da cintura,e é quase impossível de ser visualizada.

A situação é similar com relação aos explosivos,quando foram revestidos com camadas de plástico e alojados em regiões estratégicas do corpo, os explosivos também não foram detectados pelos scanners.

Estudos mostram que é possível instalar um vírus nos computadores do scanner simplesmente utilizando um $\mathrm{QR}^{9}$ estampado em uma camisa, fazendo com que o scanner mostre uma imagem de um outro passageiro que já passou pelo scanner.

${ }^{9}$ QR: código de barras bidimensional que pode ser facilmente lido usando a maioria dos telefones celulares equipados com câmera. 
Revista Científica do Corpo de Bombeiros Militar de Pernambuco Seção 2 - Artigos de Opinião

Artigo publicado no Vol.04 №10 - Edição de JUL a DEZ 2018 - ISSN 2359-4837(online)

Versão on-line disponível em: http://www.revistaflammae.com.

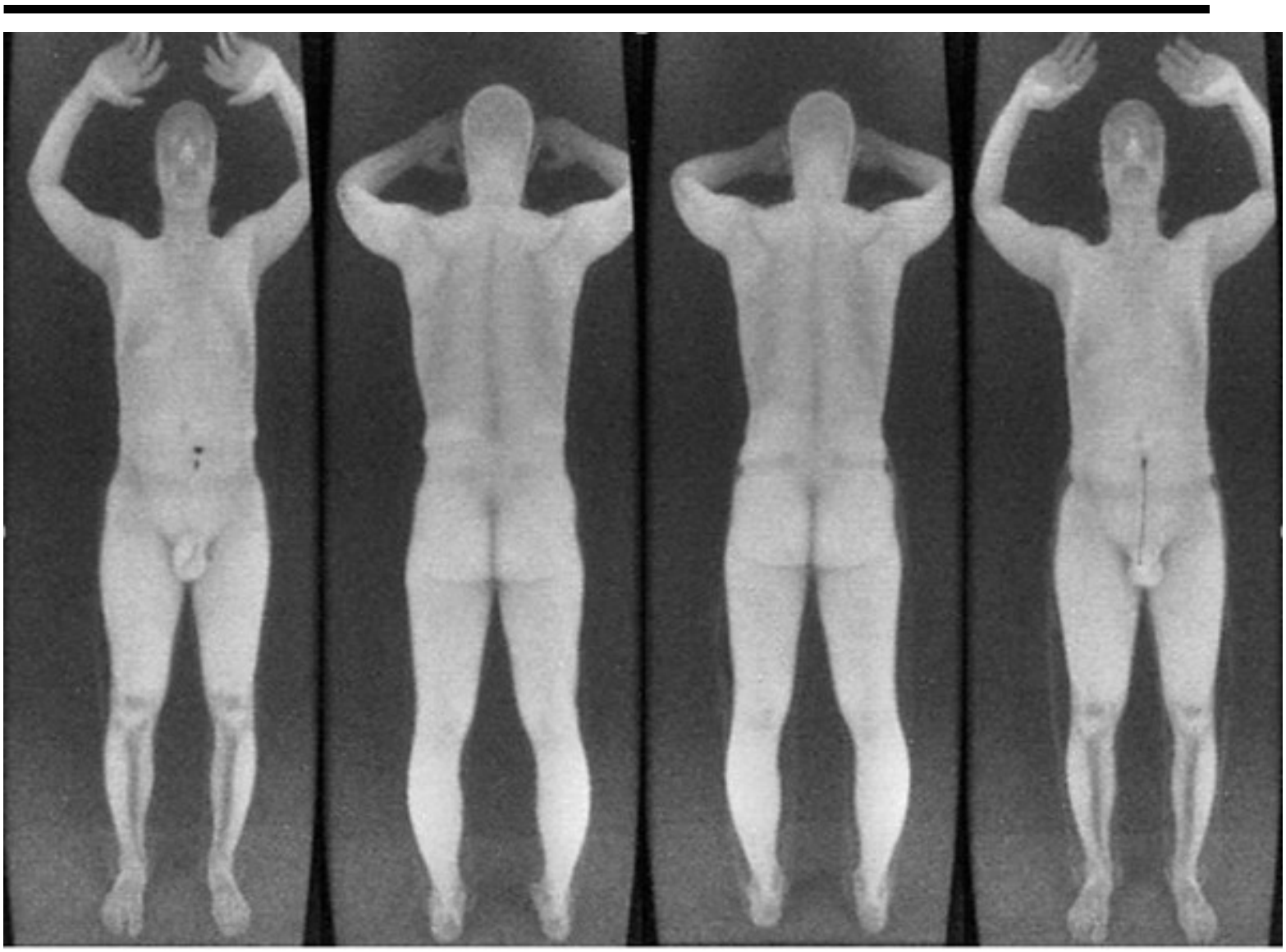

Figura 03: Homem carregando uma arma a região lateral direita da cintura. (SIMULSCAN, 2007).

\section{APRESENTAÇÃO E ANÁLISE DOS RESULTADOS}

O objetivo desta pesquisa foi diagnosticado as substâncias químicas difíceis de serem detectadas pelos sistemas de segurança dos aeroportos e que podem ser transportadas em aeronaves provocando atos terroristas.

Inicialmente buscamos identificar o termo terrorismo nos autores Pella (1928), Sottile (1938) e Diniz (2004) que apresentam seus próprios conceitos, motivos e finalidades sobre os atos terroristas em conformidade com $\mathrm{o}$ momento histórico de cada autor.

O quadro 2 abaixo apresenta de forma sucinta os principais pontos apresentados pelos dos referidos autores que foram coletados na pesquisa. 
Revista Científica do Corpo de Bombeiros Militar de Pernambuco

Seção 2 - Artigos de Opinião

Artigo publicado no Vol.04 №10 - Edição de JUL a DEZ 2018 - ISSN 2359-4837(online)

Versão on-line disponível em: http://www.revistaflammae.com.

Quadro 2: Definição de terrorismo:

\begin{tabular}{|c|l|}
\hline \multirow{3}{*}{ Pella } & \multicolumn{1}{|c|}{ Contextualizando terrorismo } \\
& $>$ Diferencia terrorismo e pirataria. \\
& $>$ Ambos utilizando o terror como instrumento de força. \\
& e lucro próprio. \\
\hline \multirow{3}{*}{ Sottile } & $>$ Classifica de maneira ampla o terrorismo. \\
& $>$ Motivação do ato, seja ele um ato social ou privado. \\
& $>$ Aspecto espacial, nacional, interno ou terrorismo \\
& $>$ Anternacional e de execução direta ou indireta. \\
\hline \multirow{3}{*}{ Diniz } & $>$ Meta política, utilizando o terror como instrumento de \\
& força. \\
& $>$ Tem como objetivo alterar o comportamento do inimigo \\
& para então derrota-lo.
\end{tabular}

Fonte: DINIZ, 2004; PELLA,1928;SOTILE, 1938.

No que se refere as substâncias químicas, encontramos uma grande variedade de produtos, que podem ser utilizados de forma a danificar a estrutura de uma aeronave ou simplesmente espalhar pânico entre os passageiros, com o intuito de fragilizar a segurança de vôo.

As diversas possibilidades com as combinações das substâncias químicas,podem servir aos diferentes propósitos, objetivos e finalidades do ato terrorista. Entre elas o fácil acesso e disponibilidade dos produtos químicos no aspecto comercial, sua manipulação, armazenamento, transporte e a dificuldade de serem identificados, tornam esses elementos os mais escolhidos para os atos terroristas.

Observamos que a utilização de scanner corporais para a detecção de substâncias químicas que podem ser embarcadas e utilizadas no voo para 
Revista Científica do Corpo de Bombeiros Militar de Pernambuco

Seção 2 - Artigos de Opinião

Artigo publicado no Vol.04 №10 - Edição de JUL a DEZ 2018 - ISSN 2359-4837(online)

Versão on-line disponível em: $\underline{\text { http://www.revistaflammae.com. }}$

atentados terroristas ainda é polêmica, devido a não detecção direta das mesmas.

Os scanners demonstraram grande vulnerabilidade, uma vez que o seu método de funcionamento para gerar imagens é baseado na densidade dos objetos presentes nas bagagens, e esse fator dificulta a interpretação das informações transmitidas pelo equipamento. Mesmo os scanner corporais apresentam limitações quando se trata de detectar os objetos que não devem ser embarcados. Em virtude da geração de imagens não tridimensionais, objetos e substâncias, podem ser facilmente ocultadas em recipientes plásticos ou em partes do corpo.

\section{DISCUSSÃO}

A definição de terrorismo para Diniz (2004), Pella(1928) e Sottile(1938) são em verdade complementares, no sentido que aborda o terrorismo como uma maneira de luta política, com o objetivo de alterar rapidamente a correlação de forças, utilizando o terror como instrumento, sendo seu objetivo causar uma alteração no comportamento de um suposto adversário para levalo a uma derrota. A partir do entendimento apresentado pelos autores utilizados na pesquisa, pode-se considerar o ato terrorista como uma ação provocada a uma ou mais pessoas, de forma direta e indireta, com ou sem o uso de força física, com a intenção de promover pânico e/ou o terror a nível nacional ou internacional. Importante ressaltar que para além da motivação de promover o terror e pânico,o ato terrorista provoca, profundas modificações nos aspectos sociais, culturais, políticos e econômicos,como aponta Diniz (2004) e Sottile (1938).

Algumas das substâncias químicas citadas na pesquisa já foram utilizadas em atos terroristas ao longo da história. Como apresentado, a fabricação de explosivos a partir da combinação de substâncias é muito simples. De acordo com William Powell (1971) todas as receitas de bombas 
presentes no livro The Anarchist Cookbook são reais e que se feitas de maneira como é ensinado no livro podem ser fabricadas em uma cozinha comum sem maiores dificuldades. Ele afirma que os explosivos, se forem utilizados de forma adequada, podem se tornar em uma ferramenta muito eficiente para atos terroristas.

Conforme apresentado na pesquisa os estudos realizados por diferentes universidades americanas, demonstraram que os scanners corporais são facilmente burlados com armas de fogo e explosivos quando cobertos por camadas de plástico e colocados de maneira estratégicas em regiões do corpo,tornando-os ineficiente para a detecção dos objetos. O fabricante de scanners, Rapiscan System, declarou que em muitas situações um simples objeto de tamanho e densidade maior pode dificultar a leitura de outros objetos presentes em uma bagagem, uma vez que os scanners utilizam o fator densidade como parâmetro para identificação de objetos presentes nos passageiros e suas bagagens.

Nos principais atentados citados nesse trabalho, os terroristas conseguiram embarcar com substâncias químicas e explosivos sem dificuldade. Quando Richard Colvin Reid tentou embarcar com um explosivo escondido em seu sapato com o objetivo de derrubar o vôo 63 da empresa American Airlines, ele foi detido antes da fiscalização de bagagens, mas o processo judicial deixou claro que o que chamou a atenção dos seguranças foi a sua aparência e que ao ser interrogado afirmou que o detector de metais não acharia os explosivos em seus sapatos pelo fato de serem explosivos plásticos. No caso do atentando de Bojinka, Youseff embarcou normalmente, levando consigo uma garrafa preenchida com nitroglicerina e demais objetos utilizados para a fabricação de uma bomba que matou um passageiro, deixou 10 feridos e colocou em risco a segurança do o vôo 434 da Philippine Airlines.

No atentado às "torres gêmeas", os objetos que passaram pelo sistema de fiscalização de bagagens, foram utilizados para simular uma bomba espalhando o pânico aos passageiros permitindo assumir o controle da 
Revista Científica do Corpo de Bombeiros Militar de Pernambuco

Seção 2 - Artigos de Opinião

Artigo publicado no Vol.04 №10 - Edição de JUL a DEZ 2018 - ISSN 2359-4837(online)

Versão on-line disponível em: http://www.revistaflammae.com.

aeronave, colocando em prática todo o plano de ataque. Isso prova que não é preciso muito poder de fogo para tomar o controle de uma aeronave comercial.

\section{CONCLUSÃO}

A partir do objetivo de indicar as fragilidades do sistema de fiscalização de substâncias químicas que podem ser facilmente embarcadas e utilizadas para um ato terrorista em aeronaves, verificamos que as motivações para a execução de um ato terrorista se modificaram ao longo da história. Conforme registrado pode-se considerar que o comportamento dos Zelotes, motivados por questões de cunho religiosos, são apontados como as primeiras ações de atos terroristas. Com o passar do tempo outras motivações se apresentaram para justificar tais atos, como os aspectos político, social, cultural e econômico.

Uma vez que a valoração de um ato terrorista está diretamente interligado e se encontra em constante transformação, seus impactos podem atingir uma pessoa, um grupo e até mesmo uma nação, provocando alterações em seus comportamentos sociais, culturais, políticos e econômicos.

Da mesma forma que as motivações se modificaram através do tempo, as ferramentas utilizadas para realizar os atos terroristas se tornaram mais elaboradas e cada vez mais difícil de ser identificadas e com uma maior capacidade de destruição, e alterando significativamente a apreensão psicológica diante de tais atos.

Analisando os atentados terroristas citados no trabalho fica evidente que com uma simples substância química ou objetos comuns é possível tomar o controle de uma aeronave comercial, afetar a segurança do vôo ou até mesmo destruí-la.

Todas as substâncias químicas relatadas no trabalho, possuem características favoráveis para atos terroristas e principalmente atos envolvendo a aviação. São substâncias de fácil obtenção no comercio, podendo ser facilmente armazenadas em diferentes recipientes sem levantar 
suspeita e que em mesmo pequenas quantidades podem causar grandes impactos para o ato terrorista. Um dos fatores que mais chamou a atenção durante a pesquisa foi o fácil acesso as informações sobre métodos de guerrilhas, fabricação de bombas, armas e armadilhas com explosivos. Ao realizar buscar na internet para o levantamento de informações uteis na elaboração dessa pesquisa, em poucas horas foi possível ter acesso a esses conteúdos, com informações que vão desde aos locais de aquisição e compra até a maneira de construir e manipular materiais para confecção de explosivos.

A leitura de imagem realizada pelos scanners se mostrou limitada e imprecisa, além de exigir do agente aeroportuário que opera esses aparelhos uma qualificação para identificação de objetos e/ou substâncias que são colocadas nas bagagens. Mesmo com a utilização dos scanners corporais houve dificuldade de identificação durante a leitura de armas de fogo e explosivos, devido ao processo de captação de imagens e seus sistemas operacionais usados nestes equipamentos.

O Brasil é um pais com poucos relatos de atentados terroristas, seja com motivações religiosas, similares ao que acontece em outras partes do mundo, mas por outro lado se apresenta como um país muito propício para um terrorismo político interno nacional, semelhante ao que aconteceu na Revolta de Aragarças.

Nos últimos anos é crescente o número de pessoas que utilizam o transporte aéreo como opção de ir e vir. De acordo com os dados coletados para a pesquisa a estrutura de fiscalização de passageiros e bagagens, indica que na maioria dos aeroportos do pais, é inexistente ou deficitário, e não conta com equipamentos básicos como raio-x, scanners de bagagens e corporal.

Visando a melhoria dos serviços de segurança na aviação brasileira e com a finalidade de diminuir as possibilidades de que atos terroristas possam ocorrer, é importante, por parte das autoridades e órgãos que tratam da segurança aeroportuária nacional, o planejamento e execução de ações que 
Revista Científica do Corpo de Bombeiros Militar de Pernambuco Seção 2 - Artigos de Opinião

Artigo publicado no Vol.04 №10 - Edição de JUL a DEZ 2018 - ISSN 2359-4837(online)

Versão on-line disponível em: http://www.revistaflammae.com.

venham a diminuir ou controlar o acesso à informações sobre aquisição e compra de substância utilizados na confecção de explosivos.

Nesse sentido o controle na venda de produtos, divulgação de informações sobre fabricações de explosivos devem ser acompanhadas/monitoradas pelos órgãos competentes, acima de tudo, deve ser desenvolvido um novo sistema de fiscalização com a possibilidade de identificação de substâncias e não apenas imagens representadas por densidade dos objetos presentes nas bagagens e que sejam efetivamente implantados nos aeroportos nacionais.

As informações apresentadas são fundamentais podem servir para ampliação e continuidade de investigações futuras dentro desse tema.

\section{REFERÊNCIAS}

BONNER, R; WEISER, B. Echoes of Early Design to Use Chemicals to Blow Up Airliners. The New York Times, New York, 11 Agosto de 2006.

CASELLA, P. B. Direito internacional, terrorismo e aviação civil. São Paulo: QuartierLatin, 2006.

CUNHA, L. O. Estudo de Plano de fogo para otimização dos custos de transporte e britagem. 2013. Tese (Graduação em Engenharia Civil) Faculdade de Engenharia, Universidade Federal de Juiz de Fora. Juiz de Fora.

DEPARTMENT OF THE ARMY TECHNICAL. Improvised Munitions Handbook, TM 31-210. Disponível em:<http://gunfreezone.net/wpcontent/uploads/2016/03/improvised-munitions-handbook.pdf>. Acesso em: 28 ago. 2017. 
Revista Científica do Corpo de Bombeiros Militar de Pernambuco Seção 2 - Artigos de Opinião

Artigo publicado no Vol.04 №10 - Edição de JUL a DEZ 2018 - ISSN 2359-4837(online)

Versão on-line disponível em: $\underline{\text { http://www.revistaflammae.com. }}$

DINIZ, E. Compreendendo o fenômeno do terrorismo.2004 Disponível em: $<$ https://ciberativismoeguerra.files.wordpress.com/2016/09/diniz-do-ofenomeno-do-terrorismo.pdf>. Acesso em 28 ago. 2017.

FOLHA.COM. Aeroporto do Rio começa a usar scanner corporal; outras 3 cidades terão equipamento, notícia de 7/5/2010, Disponível em: $<$ https://noticias.bol.uol.com.br/brasil/2010/05/07/aeroporto-do-rio-comeca-ausar-scanner-corporal-outras-3-cidades-terao-equipamento.jhtm>. Acesso em: 2 nov 2017.

JOSEFO, F.; IBÁÑEZ, J. M. N. Las guerras de los judíos.1952.Disponível em: $<$ http://www.ataun.net/bibliotecagratuita/Cl\%C3\%A1sicos\%20en\%20Espa\%C3 \%B1ol/Flavio\%20Josefo/Las\%20guerras\%20de\%20los\%20jud\%C3\%ADos.pdf >. Acessoem 20 ago 2017.

Let's Roll: The Story of Flight 93. Direção: Chris Oxley,Produção: Hazel Coe, 2002.Disponívelem:

$<$ https://www.youtube.com/watch?v=GUrUQN0m79o $>$.Acesso em: 16 ago. 2017.

MIGUEZ, J. M. G. 0 primeiro sequestro aéreo da história da humanidade: aeródromo de Aragarças - GO. 2. ed. Goiânia: Kelps, 2008. 134 p.

POWELL, W. The Anarchist Cookbook.1971Disponivelem: $<$ https://uniteyouthdublin.files.wordpress.com/2015/01/anarchist-cookbookwilliam-powell.pdf>. Acessoem: 18 jun 2017. 
Revista Científica do Corpo de Bombeiros Militar de Pernambuco Seção 2 - Artigos de Opinião

Artigo publicado no Vol.04 №10 - Edição de JUL a DEZ 2018 - ISSN 2359-4837(online)

Versão on-line disponível em: http://www.revistaflammae.com.

RAPOPORT, D. C. Fear and Trembling: Terrorism in Three Religious

Traditions.American Political Science Association, 1984.Disponível em: <https://www.aclu.org/files/fbimappingfoia/20111110/ACLURM001595.pdf>.

Acesso em: 16 ago. 2017.

SANTANNA, A. C.S. Scanner corporal e o Direito de Personalidade.2013 Disponível em:

$<$ https://www.revistas.unijui.edu.br/index.php/direitoshumanosedemocracia $>$.

Acesso em: 30 Out. 2017.

SANT'ANNA, I. Plano de ataque: a história dos vôos de 11 de setembro. São Paulo: Objetiva, 2005.

SILVA. W. C. L. Blast- Efeitos da onda de choque no ser humano e nas estruturas. 2007. Tese (Mestrado Engenharia Aeronáutica e Mecânica) Instituto Tecnológico de Aeronáutica. São Jose dos Campos, São Paulo.

STEFANIDOU, M. ATHANASELIS, S.; SPILIOPOULOU, C. Healt Impacts of Fire Smoke Inhalation. Disponivel em: <https://doi.org/10.1080/08958370801975311>. Acessoem 1 set 2017. 